\title{
National laboratory policies and plans in sub-Saharan African countries: gaps and opportunities
}

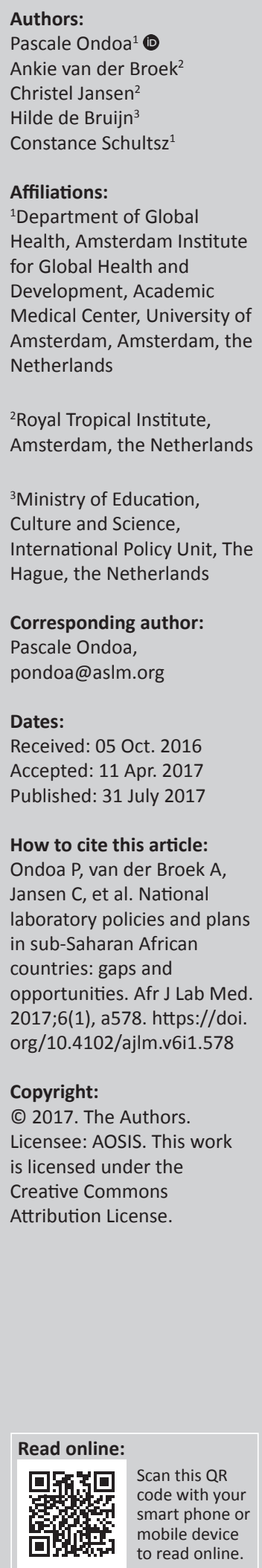

Background: The 2008 Maputo Declaration calls for the development of dedicated national laboratory policies and strategic plans supporting the enhancement of laboratory services in response to the long-lasting relegation of medical laboratory systems in sub-Saharan Africa.

Objectives: This study describes the extent to which laboratories are addressed in the national health policies and plans created directly following the 2008 momentum for laboratory strengthening.

Method: National health policies and plans from 39 sub-Saharan African countries, valid throughout and beyond 31 December 2010 were collected in March 2012 and analysed during 2013.

Results: Laboratories were addressed by all countries. Human resources were the most addressed topic $(38 / 39)$ and finances and budget were the least addressed $(<5 / 39)$. Countries lagging behind in national laboratory strategic planning at the end of $2013(17 / 39)$ were more likely to be francophone countries located in West-Central Africa (13/17) and have historically low HIV prevalence. The most common gaps anticipated to compromise the implementation of the policies and plans were the disconnect between policies and plans, under-developed finance sections and monitoring and evaluating frameworks, absence of points of reference to define gaps and shortages, and inappropriate governance structure.

Conclusion: The availability of laboratory policy and plan implementation can be improved by strictly applying a more standardised methodology for policy development, using harmonised norms to set targets for improvement and intensifying the establishment of directorates of laboratory services directly under the authority of Ministries of Health. Horizontal programmes such as the Global Health Security Agenda could provide the necessary impulse to take the least advanced countries on board.

\section{Introduction}

Laboratory services are key to the quality of healthcare but have remained a historicallyneglected component of health systems in low- and middle-income countries. The need for quality medical laboratory services to form an integrated part of the health system has been widely acknowledged by key national and international players during the past decade, resulting in the mobilisation of substantial funding earmarked for laboratory improvement in resource-limited settings. ${ }^{1,2}$

Alongside these efforts, the development of a national laboratory policy and strategic plan (NLSP) relevant to each country's needs, and aligned with its health policy(ies) and plan(s), has also been advocated. ${ }^{3,45}$ A national laboratory policy defines the vision and the mission of a country's laboratory system, whereas a strategic plan provides the corresponding roadmap guiding the process of the practical implementation of the necessary laboratory system improvement. The coherence of NLSPs with other national health guidance documents, such as national health policies, plans for development of human resources for the health sector, or disease-specific policies or plans, increases the likelihood that laboratory development strategies will be implemented.

Despite the recent prioritisation of laboratory services in global and national health agendas, various aspects of the laboratory system fail to meet standards in several countries of sub-Saharan Africa. Clinical diagnostic capacity often remains insufficient for the control of HIV, malaria, tuberculosis and other infectious diseases and for responding to the rise in incidence of noncommunicable diseases. ${ }^{6,7,8}$ In addition, the lack of laboratory-based surveillance precludes the 
timely identification of emerging infectious disease threats., ${ }^{9,10}$ The recent Ebola virus disease epidemics ${ }^{11}$ and the paucity of systematic data on the antimicrobial resistance ${ }^{12,13}$ of key bacterial pathogens are two dramatic examples illustrating the lack of laboratory capacity to either respond to or anticipate public health events of national or international concern. The persistent shortage of laboratory workers in many countries of sub-Saharan Africa ${ }^{14}$ also highlights that crucial needs are still unmet.

The primary aim of this study was to describe to what extent laboratory services were addressed in the round of national health policies and strategies created by sub-Saharan African countries following the 2008 Maputo Declaration. ${ }^{5}$ The profile of countries lagging behind the process of laboratory strategic planning was explored.

\section{Methods}

We conducted a desk review of national health policy documents. Eligible documents had to be valid throughout and beyond 31 December 2010 and were collected in March 2012. No updated or new policies were added after document collection was closed. The analysis was completed at the end of 2013.

\section{Selection of countries and documents}

Sub-Saharan African countries identified by the World Health Organization as experiencing a crisis in human resources for health ${ }^{15}$ or receiving support from the United States President's Emergency Plan for AIDS Relief (PEPFAR) were included in the study, ${ }^{16}$ which led to a review of 41 countries in total.

A search was carried out, per country for the following documents:

- National health strategy (or policy in case a strategy was not found).

- National human resources for health policy and/or strategy.

- National laboratory policy and/or strategy and/or operational plan.

- National HIV policy and/or strategy.

- National tuberculosis policy and/or strategy.

- National malaria policy and/or strategy.

Searches were carried out on the websites of the Ministries of Health, thematic websites (such as www.aidstar-one.com and the Roll Back Malaria website http://www.rbm.who. int/countryaction/index.html), Google, and within the networks of the Fondation Mérieux, the Association of Public Health Laboratories, the Royal Tropical Institute of the Kingdom of the Netherlands, and the Amsterdam Institute for Global Health and Development. Details on the search strategies and the web sites visited are provided in Supplementary Document 1.

\section{Additional information}

Data on the political, economic and health status of each country were retrieved from the World Bank (www. worldbank.org), World Health Organization ${ }^{17}$ and UNAIDS ${ }^{18}$ databases. Information on PEPFAR collaboration, the existence of a department of laboratory services within the Ministry of Health and the degree of advancement of national laboratory strategic planning were retrieved from the PEPFAR (www.pepfar.gov) and World Health Organization databases (http://www.who.int), Ministry of Health websites and through direct questioning of in-country laboratory stakeholders.

\section{Document review}

A data collection form was developed (Supplementary Document 2) and translated into a list of 88 codes pertaining to various aspects of national laboratory policy and strategic planning (Supplementary Document 3). The codes were grouped in broader families of codes, representing specific themes, e.g., 'attention to the public and the private sector', and according to a set of questions guiding the analysis. e.g., 'to which aspects of the laboratory do the policy and plans pay attention?'. The coding framework was applied to all the documents available for review. A core team of two members searched the documents, entered the data in the form and discussed and reviewed each other's work to reduce the risk of differences in interpretation of documents and coding of data. Following the review, and whenever necessary, the documents were screened for specific key words to ensure that all relevant sections had been properly coded and to allow description of content insufficiently covered by the coding list. Data with assigned meanings in Atlas.ti (Atlas.ti, version 6.2; ATLAS.ti Scientific Software Development $\mathrm{GmbH}$, Berlin, Germany) were transferred to SPSS (IBM SPSS Statistics, version 20 for Windows; IBM Corp., Armonk, New York, United States).

\section{Analysis}

For each country, we evaluated the compliance of policies and plans with guidance documents for laboratory policy and strategic planning, ${ }^{19}$ and the availability of concurrent and aligned national laboratory policies, strategies and operational plans according to the planning cycle. We examined the degree of harmonisation between policies and plans addressing the laboratory, the overall health sector and the development of human resources for health for each country.

Countries were categorised into groups of 'not started' versus 'started' with respect to the development and implementation of their NLSP at the time of the analysis in 2013 (Supplementary Table 1). These groups of countries were compared for proportions of low-, middle- and high-income countries or against their average HIV prevalence using the chi-square or Student's $t$-test. 
The analysis of the coded data focused on the identification of gaps and opportunities in selected areas of the laboratory system: governance, private sectors, quality and accreditation, human resources, finances and monitoring and evaluation.

Attention to laboratory services was defined by the number of times that the laboratory was specifically addressed, and was quantified by calculating the frequency of each code or group of codes per document type, country or group of countries. Chronological alignment between policies and plans was evaluated by plotting inception and expiry dates of the documents against each other for each country.

\section{Results}

In total, 126 documents from 39 countries were found for review (Figure 1).

\section{Availability of aligned national laboratory policies, strategies and operational plans}

Of the 10 countries (25.6\%) with a national laboratory policy, strategy, or operational plan available for review, one had developed a combined policy and strategic plan within a single document and nine had developed either a laboratory policy or a laboratory strategic plan.

The start and end years of the national laboratory policies, strategies or operational plans; national health policies; and national human resources for health policies or strategies of the 10 countries with a laboratory document available for review are depicted in Figure 2. Lack of chronological overlap was identified between some policies and plans. In South Africa, for instance, the foreseen implementation time frame of the human resources policy lay largely outside the foreseen implementation timeline of the national health policy. In Sierra Leone, the human resources policy had become obsolete shortly after national laboratory policy implementation started. In Rwanda, the timeline of the national policies for laboratory, for human resources, and for health were not aligned. In contrast, the Democratic Republic of Congo had perfectly coordinated the timelines of all three national policies.

The 10 national laboratory policies were screened for any reference to either the national health policy or the human resources for health plan (Table 1). Nine of 10 countries referred to their national health policy in their national laboratory plan. Six of the 10 national laboratory policy documents did not refer to human resources for health plans.

\section{Factors associated with advancement of national laboratory policy and strategic planning in sub-Saharan Africa}

Information gathered through the Association of Public Health Laboratories, PEPFAR, Fondation Mérieux, The Royal Tropical Institute and the Amsterdam Institute of

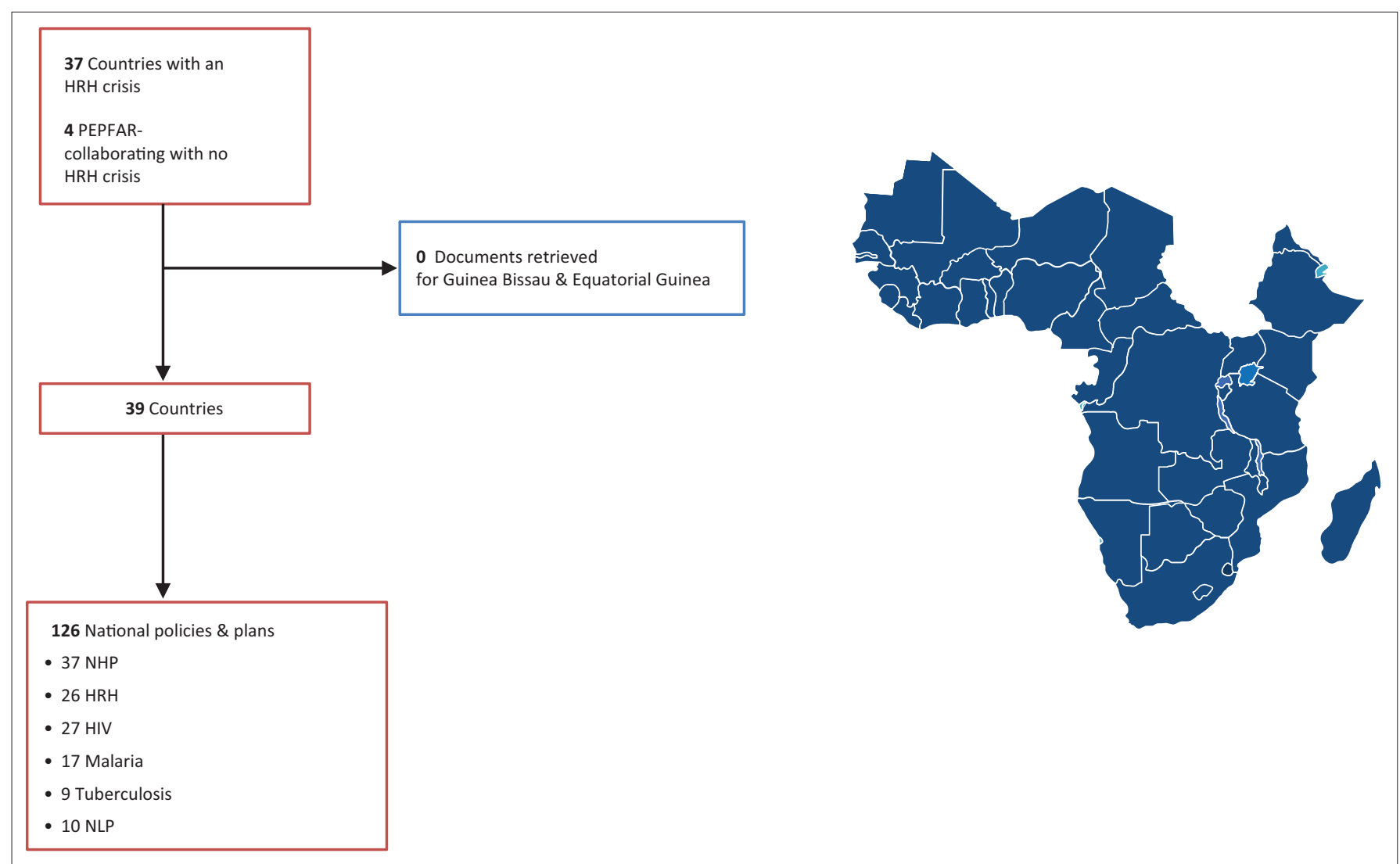

HRH, human resources for health policy or plan; NHP, national health policy or plan; NLP, national laboratory policy or plan; PEPFAR, US President's Emergency Plan for AIDS Relief.

Thirty-nine sub-Saharan African countries facing a human resources for health crisis or involved in PEPFAR collaboration were included in the analysis and are represented by the blue map. Documents were selected if they were valid through and beyond 31 December 2010. No documents could be retrieved for Guinea Bissau or Equatorial Guinea. In total, 126 national health, human resources for health, HIV, malaria, tuberculosis or laboratory policies or plans were reviewed.

FIGURE 1: Countries and documents included in the study. 
Global Health and Development networks, indicated that 17 countries were not yet engaged in initial discussions regarding national laboratory strategic planning and were categorized as 'not started'. The 23 other countries (of which 10 had a national laboratory policy available for review) were found to be either engaged in discussions, have developed a first draft, or (for the most advanced) have implemented, reviewed and evaluated their NLSP. These countries were classified as 'started'. An update of the

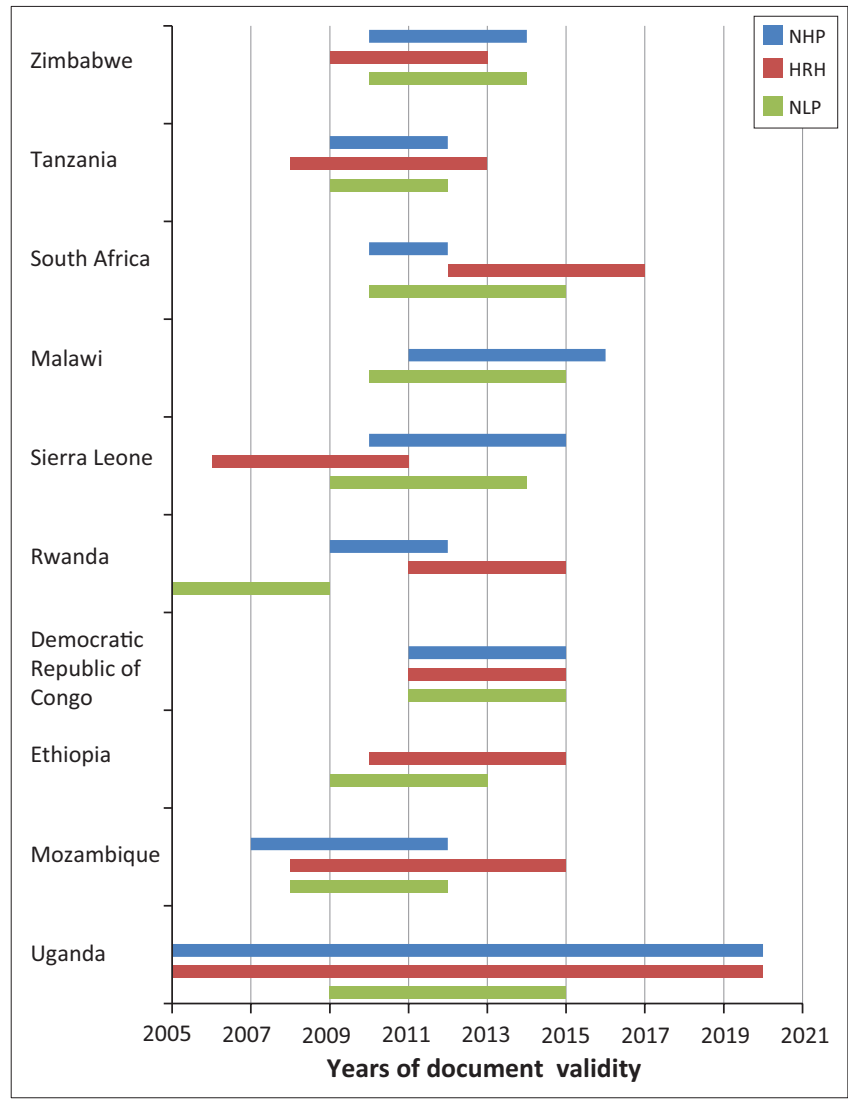

HRH, human resources for health policy or plan; NHP, national health policy or plan; NLP, national laboratory policy and strategic plan.

Gantt chart comparing the duration of validity of national health policies or plans $(\square)$, human resources for health policies or plans $(\square)$ and national laboratory policies or plans $(\square)$ for the 10 countries with a national laboratory policy or plan. The start and end dates of the respective documents were usually clearly indicated, except for the national laboratory policy of Rwanda, which did not clearly specify the end year of implementation, although the chronogram extended beyond 2010.

FIGURE 2: Overlap of validity time frames in 10 countries with a laboratory policy or plan available for review. situation in early 2017 indicated that six additional countries are now categorised as 'started', making for a total of 29 (Supplementary Table 1).

Countries that had not yet started with their NLSP were more likely to be French-speaking, be classified as lower income, or not be receiving PEPFAR support compared to countries that had already started with the process of strategic planning (Supplementary Figure $1 \mathrm{a}$ and 1b). Countries categorised as 'not started' were also those with a lower HIV prevalence as compared to countries categorised as 'started' (average prevalence $=1.9 \%$ versus 9.5\%, $p=0.001$ ). There were no differences between the two groups of countries in terms of gross domestic product, percentage of gross domestic product spent on health, health expenses per capita, and percentage of external resources for health (Supplementary Figure 1c).

\section{Main laboratory themes addressed in health policies and plans}

The most common component of laboratory services addressed across various health policies (38/39 countries) was human resources for laboratory, mostly in terms of shortages (32/39) (Figure 3). All national laboratory and tuberculosis policies, strategies, and operational plans mentioned the issue of human resources for laboratory as compared with $25 \%$ of national health policies, $24 \%$ of the human resources for health policies, $19 \%$ of HIV policies, and $15 \%$ of malaria policies (data not shown).

Other main cross-cutting components of laboratory strengthening were mentioned as follows: governance $(35 / 39)$; organizational structure and management capacity $(36 / 39)$; laboratory infrastructure, equipment and supplies (36/39); and quality assurance (34/39), all issues were predominantly mentioned in the specific context of HIV/ AIDS (34/39).

Biosafety was the least addressed cross-cutting component of laboratory services, being overlooked by 21 of the 39 countries (53.8\%). Coverage of the eight main cross-cutting components of laboratory strengthening ${ }^{19}$ was achieved in the 10 countries

TABLE 1: Cross references between national laboratory, national human resources for health and national health policies or plans.

\begin{tabular}{lll}
\hline $\begin{array}{l}\text { Countries with a laboratory } \\
\text { policy/plan }\end{array}$ & $\begin{array}{l}\text { Reference to health policy/plan within the laboratory } \\
\text { policy/plan }\end{array}$ & Reference to the human resources for health policy/plan \\
\hline Tanzania & Health Sector Strategic Plan III from 2009-2015 & No \\
\hline Malawi & Ministry of Health strategic plan 2007-2010 (previous to current one) & HRH strategic plan (not available for the analysis) \\
Rwanda & No & No \\
Zimbabwe & National Health Policy 2008-2012 (previous to current one) & No \\
Sierra Leone & Health Policy 2002 and Health Strategic Plan (no specific year) & National Human Resource Plan for Health 2006 (previous to \\
South Africa & $\begin{array}{l}\text { African National Congress National Health Plan 1994 (previous to } \\
\text { current one) }\end{array}$ & No \\
Mozambique & Health Sector Strategic Plan (no specific year) & No (no plan found for analysis) \\
Ethiopia & Health Sector Development Programme & $\begin{array}{l}\text { Plan National de développement des ressources humaines pour } \\
\text { la santé (2011-2015) }\end{array}$ \\
$\begin{array}{l}\text { Democratic Republic } \\
\text { of Congo }\end{array}$ & $\begin{array}{l}\text { Politique Nationale de Santé and Plan National de Développement } \\
\text { Sanitaire with details on strategies and policy elements that are } \\
\text { integrated in the laboratory plan (2011-2015). }\end{array}$ & HRH plan (no specific year) \\
\hline Uganda & National Health policy and National Health Strategic Plan (no specific year) & .
\end{tabular}

HRH, human resources for health 


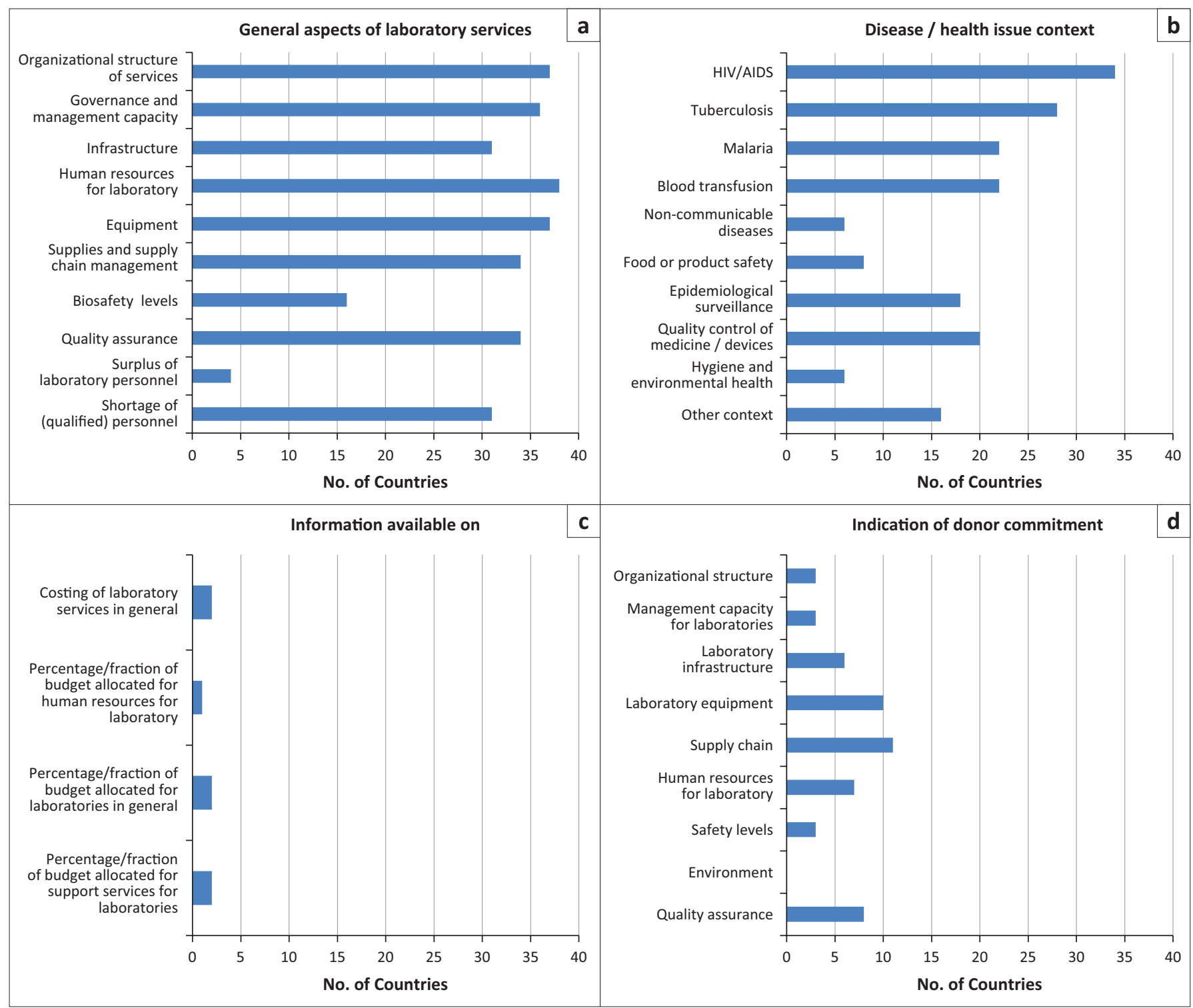

The 126 documents for 39 countries were screened for content pertaining to the various laboratory questions. The 88 codes translating the different laboratory aspects were grouped into families of codes representing main themes. The blue bars represent the number of countries addressing each laboratory theme, irrespective of the number of time a theme was addressed across the various policies and plans for that particular country. General aspects of laboratory services were mentioned in most policies and plans (a); human resources for health was addressed by 38 of the 39 countries across the various policies and plans. A majority of policies and plans mentioned laboratory services in the context of HIV/AIDS (b). Very few policies and plans included information on costing for laboratory services or mentioned what percentage or fraction of health budgets were allocated for laboratory-related costs (c). Indications of donor commitment were most often found with respect to supply chain or laboratory equipment (d).

FIGURE 3: Attention to laboratory aspects in country policies and plans $(\mathrm{N}=39)$.

with a national laboratory policy. Among the 29 countries without a dedicated laboratory policy or plan, four addressed all core aspects of laboratory strengthening through other type(s) of plans, while the majority overlooked one $(n=15)$ or several $(n=10)$ of the eight cross-cutting components concerning medical laboratories.

Budget allocation and donor support for laboratory services were scarcely covered (Figure 3), regardless the type of document studied. The percentage of health budgets earmarked for laboratory services or human resources was mentioned by only two countries. Among the 39 countries, donor support was hardly addressed in the context of the organisational structure of laboratories $(n=2)$, biosafety $(n=2)$, or management capacity $(n=4)$, and more frequently in the context of laboratory equipment $(n=10)$ and supply chain $(n=11)$.

\section{Most significant weaknesses identified in policies and plans}

\section{Little attention to financing}

Regardless of the type of plan, very limited attention was devoted to the budget available or needed for the provision of laboratory services or for the implementation of laboratory improvement strategies. Evidence for a budget line dedicated to laboratory services was found in two out of the 39 countries. Of the 37 national health plans, three reported a specific part of the health budget allocated to support services and one indicated budget allocation for laboratory staff in general. Eleven countries provided a budget dedicated to specific strategies to improve laboratory services in their national health plans.

All 10 national laboratory policies reported insufficient government funding for laboratory services. At the same 
time, seven of these did not provide the percentage of the overall government health budget available for laboratory services. An overview of donor contributions was also lacking in all of the documents reviewed. Information on costing, budgeting and identification of funding sources for the implementation of the overall as well as specific components of the NLSP were largely missing. Funding from external partners was often mentioned in the context of the provision of equipment and supplies, or in relation to specific diseases, but rarely in the area of human resources development.

\section{Lack of practical framework to monitor and evaluate laboratory services and national laboratory policy implementation}

No indicators were proposed to measure the performance of laboratory services in any of the national laboratory policies. A monitoring and evaluation section to follow the implementation of the plan was included in four of the seven NLSP (Democratic Republic of Congo, Malawi, Tanzania and Zimbabwe), with only one (Democratic Republic of Congo) providing sufficiently detailed indicators linked to a budget and a chronogram.

\section{Insufficient attention to the creation of laboratory departments within Ministries of Health}

Only five countries described streamlining the administration of their laboratory systems through a laboratory directorate falling directly under the authority of the Ministry of Health, as recommended by the Maputo Declaration (Table 2). The other countries organised their laboratory services through a department responsible for, but not dedicated to, laboratories $(n=13)$, through a single service provider or research institution $(n=4)$, or through multiple entities within the Ministry of Health and provider institutions $(n=7)$. For 10 countries, no information on the laboratory coordinating body could be found.

Of the seven national laboratory policies of countries with no directorate of laboratories, only two national laboratory policies explicitly aimed at raising the profile of laboratory services through one department within the Ministry of
Health. Nineteen of the 21 national health policies (90.5\%) addressing laboratory governance were from countries that did not yet have a directorate of laboratory services under the Ministry of Health. Of these, only two proposed the creation of a directorate of laboratories within the Ministry of Health as a way to improve the governance of laboratory services.

\section{Poorly-informed situation analysis of the private laboratory sector}

Private laboratories were addressed by 28 of 39 countries (71\%) and by all national laboratory policies (data not shown). Five national laboratory policies described private laboratories as being separate from the public laboratory network. Six national laboratory policies, two human resources for health plans, one HIV policy and one malaria policy from eight of the 39 countries $(84 \%)$ provided some information on the number of facilities operating in the private sector or the percentage of the population they serve or the laboratory staff they employ. The governance of the private sector and private sector links with the national laboratory network were left largely unclear in most of the policies and plans reviewed. Only three national laboratory policies provided some indication that the private sector was functioning as part of the overall laboratory network.

The list of participating stakeholders and summaries of meeting proceedings attached to the policies and plans suggested that the private laboratory sector and economic actors susceptible to support the implementation of the plan were only marginally involved in the development of the laboratory documents.

\section{Insufficient points of reference for establishing workforce shortage reduction strategies}

Twenty-six countries reported laboratory workforce shortages in their national health policies and/or human resources for health policies, four mentioned overstaffing and nine did not explicitly discuss shortages in the laboratory workforce. Among the countries indicating shortages, six did not provide any information on the category of laboratory workers concerned, 10 did not specify a point of reference to

TABLE 2: Type of laboratory governance in the 39 sub-Saharan African countries studied.

\begin{tabular}{|c|c|c|c|c|}
\hline $\begin{array}{l}\text { Dedicated Laboratory } \\
\text { Directorate in Ministry } \\
\text { of Health }(n=5)\end{array}$ & $\begin{array}{l}\text { Department responsible for } \\
\text { laboratories and other sectors } \\
\text { (e.g., Pharmacy) }(n=13)\end{array}$ & $\begin{array}{l}\text { Provider/research institution } \\
\text { responsible for laboratory }(n=4)\end{array}$ & $\begin{array}{l}\text { Multiple departments within } \\
\text { Ministry of Health dedicated } \\
\text { to laboratory }(n=7)\end{array}$ & Unknown $(n=10)$ \\
\hline Burkina Faso & Benin & Ethiopia (EHNRI) & Uganda & Botswana \\
\hline Sierra Leone & Central African Republic & South Africa (NHLS) & Zambia & Congo \\
\hline Zimbabwe & Chad & Mali (INRSP) & Namibia & Ghana \\
\hline \multirow[t]{8}{*}{ Democratic Republic of Congo } & Côte d'Ivoire & & Swaziland & Eritrea \\
\hline & Guinea & & Liberia & Angola \\
\hline & Mauritania & & & Lesotho \\
\hline & Niger & & & Nigeria \\
\hline & Togo & & & Malawi \\
\hline & Cameroon & & & \\
\hline & Madagascar & & & \\
\hline & Tanzania & & & \\
\hline
\end{tabular}

EHNRI, Ethiopian Health National Research Institute; INRSP, Institut National de Recherche en Santé Publique; NHLS, National Health Laboratory System; NRL, National Reference Laboratory 
define the shortage and 20 did not have any information on the attrition rate of the laboratory workforce (Supplementary Table 2). Three countries defined shortages against positions actually available (vacancies), three against current or projected workload, and 11 against national norms based on tier-specific staffing requirements.

National laboratory policies generally included more aspects of human resources for laboratory in their plans as compared to any other type of policy and plan (Supplementary Figure 2). However, eight of 10 NLP did not provide data on the categories of staff affected nor on points of reference to define the shortages. Clear strategies, targets and funding sources to improve the availability, capacity and performance of the workforce were not specified.

\section{Vision and plan for laboratory accreditation not referred to in national laboratory policies and plans}

Nine of the 10 national laboratory policies planned to use laboratory accreditation as a way to promote quality laboratory services, in line with the recommendations of the Maputo Declaration. However, roadmaps explaining how countries intend to move toward accreditation across diseases, at different tiers of the laboratory system and given the resources available were rarely provided or referred to (Box 1). Ethiopia was an exception, detailing an initial achievement of disease-specific international accreditation of polio and HIV reference laboratories, followed by a progressive expansion to other diseases and down to the regional level. Certification of laboratories based on compliance to national standards was never mentioned as a strategy to ensure the quality of laboratory services at lower tiers.

\section{Discussion}

The attention devoted to medical laboratories in general, and to human resources in particular, in the round of national health policies and strategic plans that appeared shortly after the international momentum for the strengthening of laboratory services underscores the robust uptake of the recommendations of the Maputo Declaration in the majority of sub-Saharan African countries. However, 17 countries $(43 \%)$ were still lagging behind the process at the time of the analysis in 2013. Strikingly, countries with less advanced laboratory policies and plans were mainly located in West

BOX 1: Strategies for laboratory accreditation described in the 10 national laboratory policies and plans.

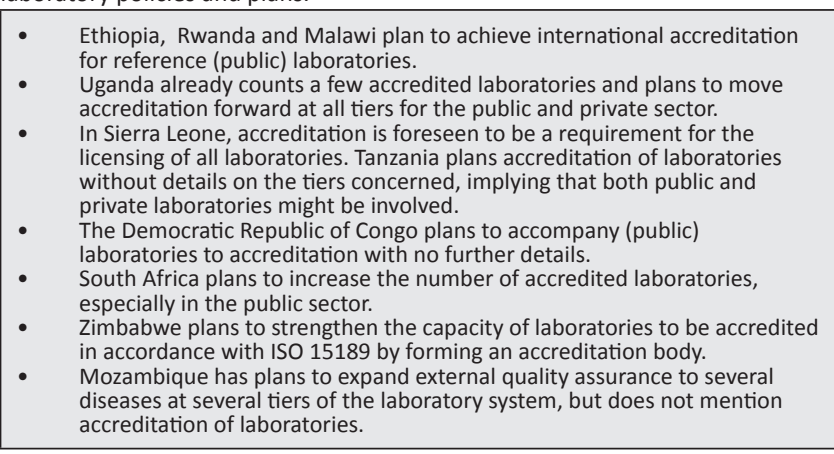

and Central francophone Africa with a history of low HIV prevalence and limited PEPFAR investment. Combined with the observation that most laboratory issues were addressed in the context of HIV/AIDS, this finding illustrates the key role that international, vertical, disease-specific programmes, such as PEPFAR and the Global Fund, have played in prioritising and funding the development of laboratory systems in the region. At the same time, the report suggests that areas with smaller HIV epidemics benefited less from available opportunities to advance their national laboratory policy and strategic planning.

More equitable access to technical and financial resources to advance laboratory systems through adequate policy and planning could be achieved by diagonalising vertical and horizontal programmes in such a way that disease-wide, multi-sectoral and whole-of-government programmes for health improvement include the improvement of laboratory systems for the control of specific diseases. The Global Health Security Agenda goal to accelerate the achievement of International Health Regulations targets could offer a momentum for this paradigm shift, by incorporating laboratory-specific targets in the effort to achieve global health security. ${ }^{20}$

This report identifies several inadequacies which should be addressed in the upcoming round of NLSP to increase the likelihood of implementation of laboratory policies and plans and support the achievement of national and global health targets.

\section{Recommendations}

\section{Application of standardised methodologies}

Consistently apply existing standardised methodologies for the development of national laboratory policies. This would ensure that no policy is formulated without a strategic plan or vice versa and that national laboratory policies are adequately aligned with other related health policies and integrate all key elements necessary for implementation. In addition, a (self-applied) national laboratory system assessment using available standardised tools, for example, the World Health Organization Laboratory Assessment Tool (LAT)-system assessment, ${ }^{21}$ Laboratory Network (LABNET) scorecard, ${ }^{22}$ and a strengths, weaknesses, opportunities, threats (SWOT) analysis of laboratory cross-cutting areas by a large inter-sectoral group of laboratory stakeholders conducted prior to the policy formulation, could facilitate the adequate prioritisation of strategic areas for improvements. Such a strictly standardised approach is ongoing for the development of national laboratory policies in Eastern Europe and central Asia, under the 'Better Lab for Better Health Initiative ${ }^{\prime 23}$ of the World Health Organization's Regional Office for Europe, with promising results.

\section{Harmonised national norms and standards}

Define and disseminate harmonised national norms and standards for various aspects of laboratories as a priority for 
international partners in laboratory development. Regional bodies, such as the African Society for Laboratory Medicine or the World Health Organization's Regional Office for Africa, could facilitate the development or the sharing and adjustment of national norms and standards available (e.g., staffing norms based on anticipated workload defined in Botswana; norms for infrastructure and equipment) from countries in similar settings. International technical partners could coordinate the development of generic costing tools for key items such as the implementation of quality management systems or laboratory information management systems or sample referral systems.

\section{Renewal of advocacy efforts}

Renew advocacy efforts for the creation of a directorate of laboratory services directly under the authority of the Ministry of Health, as recommended by the first call of the Maputo Declaration. With the correct mandate, a directorate can leverage improvements in several cross-cutting areas of laboratory systems such as development and enforcement of regulations, legislation (including the private sector), and development and application of normative standards (e.g., staffing, quality, infrastructure). The directorate would delineate important roadmaps such as national laboratory accreditation plans with linkage to laboratory-dedicated budget lines. Regional bodies and international development partners can significantly contribute to advocacy efforts, as illustrated by the RESAOLAB (Réseau d'Afrique de l'Ouest des Laboratoires) programme from Fondation Mérieux, which promoted the creation of laboratory directorates in Burkina Faso and Senegal. ${ }^{24}$

\section{Conclusions}

The conclusions and recommendations stated here are mainly based on the analysis of documents that were available for review. The authors acknowledge the possibility that the outcome of the review could have been different, if all national policies had been available for the analysis. Additionally, the documents available from public sources may have been short versions that lacked budget sections. Finally, the present situation of national laboratory policy and strategic planning is different from that in 2010, with West and Central francophone African countries such as Mali, Burkina Faso, Burundi and the Republic of Congo currently implementing their first NLSP. In addition, six countries on the continent are implementing their second round of NLSP. Moving forward, the lessons reported here can be taken on board when countries develop or revise their laboratory policies, or initiate the next round of NLSP.

\section{Acknowledgements}

The authors thank Ralph Timperi, Tsehaynesh Messele and Trevor Peter for their input to the design of the research question and the interpretation of the results. We are indebted to Julien Schijver and Merel Lammer for their contribution to the data analysis. We thank Jean-Louis
Abena, Esther Gathinji and Cleophas Malaba for sharing documents. We thank John Nkengasong for his critical review of the manuscript.

\section{Competing interests}

The authors declare that they have no financial or personal relationships which may have inappropriately influenced them in writing this article.

\section{Sources of support}

This research was supported by the African Society for Laboratory Medicine and the African Field Epidemiology Network.

\section{Authors' contributions}

P.O. and A.v.d.B. conceived and designed the research question and the analysis framework. P.O., A.v.d.B., C.J. and H.d.B. collected the documents and analysed the data. P.O., A.v.d.B., C.J. and C.S. contributed to the interpretation of the results. P.O. drafted the manuscript. A.v.d.B. and C.S. critically reviewed the manuscript.

\section{References}

1. Piot $P$, Kazatchkine $M$, Dybul $M$, et al. AIDS: lessons learnt and myths dispelled Lancet. 2009;374(9685):260-263 [Erratum in 2009;374(9690):608]. https://doi. org/10.1016/S0140-6736(09)60321-4

2. The World Bank. Cross-country laboratory network to raise East Africa's defenses against disease. Washington, DC: World Bank; 2010.

3. Nkengasong JN, Mesele T, Orloff $\mathrm{S}$, et al. Critical role of developing national strategic plans as a guide to strengthen laboratory health systems in resourceAJCPC51BLOBBPAKC

4. Nkengasong JN, Nsubuga $P$, Nwanyanwu $O$, et al. Laboratory systems and services are critical in global health: time to end the neglect? Am J Clin Pathol. 2010;134(3):368-373. https://doi.org/10.1309/AJCPMPSINQ9BRMU6

5. World Health Organization. The Maputo Declaration on strengthening of laboratory systems. Geneva, Switzerland: WHO; 2008.

6. World Health Organization. Global tuberculosis report 2015. Geneva, Switzerland: WHO; 2015.

7. Joint United Programme of HIV/AIDS. 90-90-90 - an ambitious treatment target to help end the AIDS epidemic. Geneva, Switzerland: UNAIDS; 2014

8. McNerney R. Diagnostics in developing countries. Diagnostics. 2015;5(2):200-209. https://doi.org/10.3390/diagnostics5020200

9. Tambo E, Ugwu EC, Ngogang JY. Need of surveillance response systems to combat Ebola outbreaks and other emerging infectious diseases in African countries. Infect Dis Poverty. 2014;3:29. https://doi.org/10.1186/2049-9957-3-29

10. Ftika L, Maltezou HC. Viral haemorrhagic fevers in healthcare settings. J Hosp Infect. 2013;83(3):185-192. https://doi.org/10.1016/j.jhin.2012.10.013

11. World Health Organization. Ebola situation report - 30 March 2016 [document on the Internet]. c2016 [cited 2016 Apr]. Available from: http://apps.who.int/ebola/ current-situation/ebola-situation-report-30-march-2016

12. World Health Organization. Antimicrobial resistance: global report on surveillance 2014 [document on the Internet]. c2014 [cited 2016 Apr]. Available from: http:// www.who.int/drugresistance/documents/surveillancereport/en/

13. Leopold SJ, van Leth F, Tarekegn $\mathrm{H}$, et al. Antimicrobial drug resistance among clinically relevant bacterial isolates in sub-Saharan Africa: a systematic review. J Antimicrob Chemother. 2014;69(9):2337-2353. https://doi.org/10.1093/jac/dku176

14. World Health Organization. Policies and practices of countries that are experiencing a crisis in human resources for health: tracking survey. Geneva, Switzerland: WHO; 2010.

15. World Health Organization. List of 57 countries facing Human Resources for Health crisis [document on the Internet]. c2006 [cited 2016 Apr]. Available from: www. who.int/workforcealliance/countries/57crisiscountries.pdf

16. The United States President's Emergency Plan for AIDS Relief (PEPFAR). Country operational plans [page on the Inernet]. n.d. [cited 2016 Apr]. Available from: www.pepfar.gov/countries/index.htm

17. World Health Organization. Health accounts [page on the Internet]. c2010 [cited 2016 Apr]. Available from: http://www.who.int/health-accounts/en/ 
18. Joint United Programme of HIV/AIDS. UNAIDS Report on the global AIDS epidemic | 2012 [document on the Internet]. c2012 [cited 2017 May 03]. Available from: http://www.unaids.org/sites/default/files/media_asset/20121120_UNAIDS Global_Report_2012_with_annexes_en_1.pd

19. World Health Organization - Regional Office for Africa; US Centers for Disease Control and Prevention. Guidance for development of national laboratory strategic plans. Atlanta, GA: CDC; 2010.

20. US Centers for Disease Control and Prevention. Global Health Security Agenda: action packages (GHSA). Atlanta, GA: CDC; 2014.

21. World Health Organization. Laboratory Assessment Tool. Annex 1 Laboratory assessment tool/system questionnaire [document on the Internet] c2012 [cited 2016 Apr]. Available from: http://www.who.int/ihr/publications/ Annex1_LAT.pdf?ua $=1$

22. Ondoa P, Datema T, Keita-Sow M-S, et al. A new matrix for scoring the functionality of national laboratory networks in Africa: introducing the LABNET scorecard. Afr Lab Med. 2016;5(3), 9 pages. https://doi.org/10.4102/ajlm.v5i3.498

23. Brown CS, Zwetyenga J, Berdieva $M$, et al. New policy formulation methodology paves the way for sustainable laboratory systems in Europe. WHO Public Health Panorama. 2015;1(1):41-47.

24. Delorme L, Machuron JL, Sow I, et al. [RESAOLAB: West African network of laboratories to enhance the quality of clinical biology] [Article in French]. Bull Soc Pathol Exot. 2015;108(1):36-40. https://doi.org/10.1007/s13149-014-0378-1 


\section{Supplementary Materials \\ Table of Contents}

\begin{tabular}{ll}
\hline Label & Title \\
\hline Supplementary Document 1 & Search strategy \\
Supplementary Document 2 & Analysis template \\
Supplementary Document 3 & Code list \\
Supplementary Table 1 & Status of national laboratory strategic plans in sub-Saharan African countries in 2013 and 2017 \\
Supplementary Table 2 & Evidence for laboratory workforce shortage and attrition provided in national policies or plans \\
Supplementary Figure 1 & Comparison of groups of countries that had started versus not started the process of national laboratory strategic planning \\
Supplementary Figure 2 & Aspects of human resource development addressed in 10 national laboratory policies and 25 human resources for health policies \\
\hline
\end{tabular}

\section{Supplementary Document 1: Search strategy}

\begin{tabular}{|c|c|}
\hline Countries & \\
\hline Angola & Malawi \\
\hline Benin & Mali \\
\hline Botswana & Mauritania \\
\hline Burkina Faso & Mozambique \\
\hline Burundi & Namibia \\
\hline Cameroon & Niger \\
\hline Central African Republic & Nigeria \\
\hline Chad & North Sudan \\
\hline Comoros & Rwanda \\
\hline Congo & Senegal \\
\hline Cote d'Ivoire & Sierra Leone \\
\hline DRC & South Africa \\
\hline Equatorial Guinea & South Sudan \\
\hline Eritrea & Swaziland \\
\hline Ethiopia & United Republic of Tanzania \\
\hline Ghana & The Gambia \\
\hline Guinea & Togo \\
\hline Guinea-Bissau & Uganda \\
\hline Kenya & Zambia \\
\hline Lesotho & Zimbabwe \\
\hline \multicolumn{2}{|l|}{ Liberia } \\
\hline Madagascar & \\
\hline
\end{tabular}

Period of the search: 13-27 March 2012.

\section{Documents}

National plans, strategies, costing frames

Valid (strategies and frameworks) or published (evaluations and reports) after the expiry date of 31 December 2010

National Health Policy or Plan

National Health Strategy

National Human Resources for Health (HRH) strategy (or policy)

National Laboratory strategy (or policy)
National HIV strategy (or policy)

National tuberculosis strategy (or policy)

National malaria strategy (or policy)

Costing frameworks for the above strategies

Websites (all accessed April 2013)

http://www.who.int/countryfocus/cooperation_strategy/listofccs/en/index.html (for country cooperative strategies of World Health Organization)

http://www.erepublic.org/egovincountriesmmo/mali.html (to assess websites of all governments of countries)

http://www.globalhivmeinfo.org/SystemsManagement/Lists/Ministries $\% 20$ of $\% 20$ Health/Allltems.aspx (for all Ministries of Health)

http://www.kit.nl/smartsite.shtml?ch=FAB\&id=29313\&Part=Resources (for lots of general information on Human Resources)

http://www.kit.nl/smartsite.shtml?ch=FAB\&id=32449 (Eldis Human Resources for Health Dossier)

http://www.kit.nl/smartsite.shtml?ch=FAB\&id=32467 (HRH Global Resource Center: A global library of human resources for health)

http://www.kit.nl/smartsite.shtml?ch=FAB\&id=32196 (Human Resources for Health)

http://www.kit.nl/smartsite.shtml?ch=FAB\&id=32432 (World Health Organization Collaborating Centres Global Database. Collaborating Centres dealing with Human Resources for Health Development)

http://www.kit.nl/smartsite.shtml?ch=FAB\&id=32194 (World Health Organization Human Resources for Health)

www.theglobalfund.org/ (per country proposals can be read)

Also visit the websites of international donor organisations and initiatives: USAID, FHI, Roll Back Malaria, UNAIDS, KNCV, MSH, Partners in health, PEPFAR, JICA, USAID, MSH, Institut Pasteur, Fondation Mérieux and IRD (Institut de Recherche pour le Développement).

If documents are not yet found, do a Google search for:

"Health National Plan" - country

"Human Resources for Health" - country

"Strategic Health Plan" - country

"Health Policy" - country

"Workload study health" -country

"Health workers" - country

"Health Evaluation" - country

"Laboratory services" - country 


\section{Supplementary Document 2: Analysis template}

Country name:

Documents reviewed:

Give proper documentation details: Author, Publisher, Title, Date of publishing

National Governmental Documents:

$\cdot \cdot$

National non-Governmental Documents

..

Multilateral agencies

..

$\cdot \cdot$

Bilateral agencies

$\cdot \cdot$

Global Health Initiatives (GFATM, GAVI)

$\cdot \cdot$

World Bank

$\cdot \cdot$

Other

..

Is there evidence of existing documents on this subject that are not reviewed?

Yes/no

If yes: which documents

Websites reviewed:

Mention link and date accessed

General

HIV/AIDS prevalence/ incidence:

according to UNAIDS

according to current National Strategic/Health Plan

Tuberculosis prevalence/ incidence:

according to STOP TB

according to current National Strategic/Health Plan

Malaria prevalence/ incidence:

according to Roll Back Malaria

according to current National Strategic/Health Plan

Country identified with a Human Resources for Health crisis? Yes/no

Low income country: yes/no

Middle income country: yes/no

National health budget:

Proportion of the health budget contributed by donors: 


\section{A: Participation in development of plans:}

1: Out of the documentation is there evidence that the following stakeholders have been participating in the development of national plans?

Representative of:

Government

Ministry of Health

Ministry of Education

Ministry of Finance

Ministry of Defence

Other

Public sector laboratory services

Private non-profit sector laboratory services (e.g., non-governmental organisations, faith-based organisations)

Private sector laboratory services

Professional Health Association for Microbiologists/ Medical doctors/ Laboratory staff

Research groups

Others:

Unknown

2: Within the Ministry of Health is there a special department for:

a: Human Resources for Health: yes/no

b: diagnostic services including the lab services: yes/no

c: a separate laboratory services: yes/no

\section{B: National Health Policies and Plans:}

3: Which policies and plans exist in the country?

National Health Policy:

yes/ no/ don't know

National Health Strategic Plan:

yes/ no/ don't know

Human Resources for Health Plan:

yes/ no/ don't know

National laboratory plan:

yes/ no/ don't know

Other:

[please provide]

4: Which National Health Policies and Plans pay attention to laboratory services?

National Health Policy:

National Health Strategic Plan:

Human Resources for Health Plan:

National laboratory plan:

Other: yes/ no/ don't know

yes/ no/ don't know

yes/ no/ don't know

yes/ no/ don't know

[please provide]

5: If yes to any of the above, what type of laboratories are mentioned?

a: Public laboratory services?

a.1: Primary care level

a.2: Secondary care level

a.3: Tertiary care level

a.4: National Reference Laboratory

b: Private laboratory services?

b.1: Primary care level

b.2: Secondary care level

b.3: Tertiary care level

b.4: Other

6: Is there attention for strengthening of the public private mix in laboratory services? yes/no

Describe : 
7: Which aspects in respect to laboratory services are mentioned in the plan? (indicate in which plan information is found)

Organisational structure of laboratory services (organogram): yes/ no

Management capacity for laboratory services: yes/no

Laboratory infrastructure: yes/no

Laboratory equipment: $\quad$ yes/no

Supply chain (e.g. consumables): $\quad$ yes/no

Human resources for laboratory services: yes/no

Safety measurements: $\quad$ yes/no

Working environment: yes/no

Quality Assurance (e.g. accreditation/ standardisation of testing, supervision): yes/ no

\section{8: Are the following laboratory services mentioned separately?:}

Laboratory services in the context of HIV/AIDS: yes/ no

Laboratory services in the context of Tuberculosis: yes/ no

Laboratory services in the context of Malaria: yes/ no

Blood transfusion services yes/no

Other: [please provide]

C: Human Resources for laboratory services: (for this section the documents of all stakeholders will be analysed)

(indicate in which plan information is found)

9: Is there evidence that there is a shortage on laboratory personnel?

Yes/ no/ not clear

10: If yes, on what kind of indicators/criteria is this evidence based?

Information on current staffing coverage (lab workers related to inhabitants) in the country?:

Yes/ no/ not clear Information on the establishment for laboratory workers (the staff for which, in the public sector, a position and salary is reserved):

Information on targets for numbers of laboratory staff:

Based on workload studies:

Based on minimum packages of activities for health services:

International comparison:

Other:

Source:

Yes/ no/ not clear Yes/ no/ not clear Yes/ no/ not clear Yes/ no/ not clear Yes/ no/ not clear [please provide]

\section{1: What kind of laboratory staff is lacking?}

A: Medical laboratory scientist/medical technologist with university degree

(\#available/ \# needed)

b: Medical laboratory technicians

(\#available/ \# needed)

c: Laboratory assistants

(\#available/ \# needed)

d: Others

(\#available/ \# needed)

Source:

12a: Are there strategies to decrease the shortage on HR for health laboratories mentioned in the documents? Yes/ No/ Not clear

12b: Are these strategies accompanied by indicators?

Yes/ No/ Not clear

12c: Are these strategies accompanied by a budget?

Yes/ No/ Not clear

12d: Are responsibilities regarding the implementation of these strategies indicated?

Yes/ No/ Not clear

13: If strategies are mentioned, what kind of strategies are mentioned in the documents?

HR development

Pre-service (formal) education: yes/ no/ not clear

Recruitment strategies: yes/no/not clear

Tackling of gender inequality: $\quad$ yes/ no/ not clear 


\section{HR management}

Career development

In-service training

Retention strategies (salary and other financial incentives)

Allowing dual practice

Other incentives (e.g. housing, transport)

Staff distribution (urban/rural)

Task shifting

Other: [please provide]

14: Does the plan provide investment in the training institutions for laboratory workers?

yes/ no/ not clear

15: If yes:

a: Investment in the infrastructure (e.g. buildings, equipment)/ learning materials of these training institutions

b: Investment in lecturers/tutors of these schools

c: Other

$\mathrm{d}$ : Not specified

16: Does evidence exist about high attrition of lab personnel?

Yes/ no/ not clear

17 : If available, what is the attrition rate of laboratory staff?

Rate.../ unknown

18: If disaggregated, what is the attrition rate of:

a: Medical laboratory scientist/medical technologist with university degree:

b: Medical laboratory technicians:

c; Laboratory assistants:

d: Others:

19: Is there information on where laboratory staff migrate to?

yes/ no/ not clear

\section{0: If yes, do they migrate}

a: from public health sector to private for profit health sector

b: from public health sector to international NGO/ agencies (health)

c: to the non-health laboratory sector

d: out of the country

e: from private non-profit sector to public sector

f: from private for-profit sector to public sector

g: other

\section{D: FINANCING FOR LABORATORIES}

(indicate in which plan information is found)

\section{1: What is the total health budget for the country?}

a: Which proportion of the total government budget is earmarked for the health sector? - Budget:...

- Unknown

(source from: http://www.who.int/nha/country/en/index.html\#U)

b: How much does the government spend on health per capita in US dollar terms?- Budget:...

- Unknown (same source as A)

c: Which proportion of the total health budget is planned/used for medical support services (Lab, pharmacy and radiology?)

- Budget:...

- Unknown

e: Which proportion of the total health budget is planned/used for laboratory services?

- Budget:...

- Unknown

$\mathrm{f}$ : Which proportion of the budget for laboratories is planned/used for $\mathrm{HRH}$ ? 
- Budget:...
- Unknown

Costing:

\section{2: Are laboratory services in the national health plans costed?}

National Health Strategic Plan:

Human Resources for Health Plan:

National laboratory plan:

Other namely yes/no/ don't know

yes/ no/ don't know

yes/ no/ don't know

\section{3: Are there national or international donors that invest in laboratory services?}

yes/ no/ not clear

Source:

\section{4: If yes, Which donors?}

\section{5: Which laboratory services are supported by these donors?}

Organizational structure of laboratory services (organogram):

yes/no

yes/no

Management capacity for laboratory services:

yes/no

yes/no

yes/no

yes/no

yes/no

yes/no

yes/no

yes/no

[please provide]

Technical expertise

Other:

26: Do these donors invest in remuneration of lab staff (top up of salary/ incentives)?

yes/ no/ not clear

\section{E: IMPLEMENTATION OF PLANS}

27: Are there monitoring and evaluation reports or other documents that give evidence that laboratory components of plans implemented? a: evidence of implementation of laboratory components of NLSP yes/ no/ not clear

$\mathrm{b}$ : evidence of implementation of laboratory components of donor plans yes/ no/ not clear

28: If yes: which elements of laboratory services are implemented?

a: Describe the implemented laboratory components of NLSP:

$\mathrm{b}$ : Describe the implemented laboratory components of donor plans 


\section{Supplementary Document 3: Code list}

\section{0.}

1.0

1.1

1.2

1.3

1.4

1.5

1.6

2.1

2.2

2.3

3.1.1

3.1 .2

3.1 .3

3.2.1

3.2 .2

3.2 .3

3.2 .4

4.1

4.2

4.3

4.3.6

4.4

4.5

4.6

This relevant document was not found for review

Plan developed with multiple Ministry of Health departments

Plan developed with multiple ministries

Plan developed with public or private laboratory service providers

Plan developed with professional associations

Plan developed with researchers or universities

Plan developed with others

Unknown who participated in plan development

The Ministry of Health has a special HRH department

The Ministry of Health has a department that includes laboratory services

The Ministry of Health has a separate department for lab services

Public sector lab services mentioned in the plan

Private sector lab services mentioned in the plan

Attention for strengthening the public-private mix

Primary care level labs mentioned

Secondary level labs mentioned

Tertiary care level labs mentioned

National reference laboratory mentioned

Organisational structure of lab services mentioned in the plan

Governance and management capacity for lab services mentioned in the plan

Lab infrastructure mentioned in the plan

$\mathrm{HRH}$ for lab services mentioned in the plan

Laboratory equipment mentioned in the plan

Supplies and supply chain mentioned in the plan

Safety levels mentioned in the plan

Quality assurance of laboratory services mentioned in the plan

Other aspects of laboratory services mentioned in the plan

Laboratory services mentioned in the context of HIV/AIDS

Laboratory services mentioned in the context of Tuberculosis

Laboratory services mentioned in the context of malaria

Laboratory services mentioned in the context of blood transfusion services

Laboratory services mentioned in the context of non-communicable diseases

Laboratory services mentioned in the context of food or product safety

Laboratory services mentioned in the context of epidemiological surveillance

Laboratory services in the context of quality control of medicines/medical devices

Laboratory services mentioned in the context of hygiene and environmental health

Laboratory services mentioned in other context

Different cadres mentioned, including laboratory personnel

Different cadres mentioned, excluding laboratory personnel

Different cadres mentioned, unclear whether laboratory personnel is included

There is a surplus of laboratory personnel

There is a shortage of (qualified) laboratory personnel

There is a shortage of medical laboratory scientists/ medical technologists with university degree

There is a shortage of laboratory technicians

There is a shortage of laboratory assistants

There is a shortage of other laboratory personnel

The evidence for the shortage of laboratory personnel is based on information on current staffing coverage (laboratory workers per no. inhabitants or per facility) in the country

The evidence for the shortage of laboratory personnel is based on available positions for laboratory personnel in the public sector

The evidence for a shortage of laboratory personnel is based on the mentioning of training needs

The evidence for the shortage of laboratory personnel is based on other targets/ sources

Unknown where the qualification 'shortage' is based on

Exact attrition rate of laboratory technicians

Strategy accompanied by indicator

Strategy accompanied by budget

Strategy accompanied by responsibilities 
8.1.1 Gender issues related to HRH in laboratories

8.1.2 Retention strategy

8.1.3 Motivation strategy

8.1.4 Performance strategy

9.1 Pre-service (formal) education

9.2 Recruitment strategies

9.3 In-service training

9.4 Continuous professional development

9.5 Investment in career development of laboratory staff

9.6 Supportive supervision

9.7 Management

9.8 Increase salaries

9.9 Other incentives (housing, transport, non-financial)

9.91 Enhancing working conditions

9.92 Allowing dual practice

9.93 Urban-rural distribution of staff

9.94 Task shifting

9.95 Other

91.1.2 \% of the health budget allocated to support services

91.1.3\% of the health budget allocated to laboratories

91.1.4\% of the health budget allocated to laboratory HRH

92.2.1 Laboratory services in general are costed

92.2.2 This specific laboratory service is costed

93.3.1 This plan shows evidence of a donor committing to invest in organisational structure

93.3.2 This plan shows evidence of a donor committing to invest in management capacity for laboratories

93.3.3 This plan shows evidence of a donor committing to invest in lab infrastructure

93.3.4 This plan shows evidence of a donor committing to invest in lab equipment

93.3.5 This plan shows evidence of a donor committing to invest in supply chain

93.3.6 This plan shows evidence of a donor committing to invest in HRH

93.3.7 This plan shows evidence of a donor committing to invest in safety levels

93.3.8 This plan shows evidence of a donor committing to invest in environment

93.3.9 This plan shows evidence of a donor committing to invest in quality assurance

93.3.91 This plan shows evidence of a donor committing to invest in other aspects of laboratory services 
Supplementary Table 1: Status of the national laboratory strategic plan of sub-Saharan African countries in 2013 and 2017.

\begin{tabular}{|c|c|c|c|c|}
\hline Countries & Category & Comments on availability for review & NLSP status during the analysis in 2013 & NLSP status in 2017 \\
\hline Botswana & Started & Not available for review & NLSP 1 & NLSP 2 \\
\hline Eritrea & Not started & - & Not started with discussion & No further information \\
\hline Ethiopia & Started & Available for review & NLSP 1 & NLSP 2 \\
\hline Gambia & Not started & - & Not started with discussion & No further information \\
\hline Ghana & Started & - & Discussion started & NLSP 1 \\
\hline Kenya & Started & - & $\begin{array}{l}\text { NLSP } 1 \text { not valid beyond } 2010 . \\
\text { NLSP } 2 \text { in development }\end{array}$ & NLSP 2 \\
\hline Lesotho & Started & Not available & NLSP 1 & NLSP 1 \\
\hline Liberia & Not started & - & Not started with discussion & Started with discussion \\
\hline Malawi & Started & Available for review & NLSP 1 & NLSP 1 \\
\hline Namibia & Started & Not available & NLSP 1 & NLSP 1 \\
\hline Nigeria & Started & - & TWG formed & NLSP 1 \\
\hline South Africa & Started & Policy included in the review & Discussion started & TWG formed \\
\hline Sierra Leone & Started & Available for review & NLSP 1 & NLSP 2 \\
\hline Swaziland & Started & - & TWG formed & NLSP 1 \\
\hline Tanzania & Started & Available for review & NLSP 1 & NLSP 2 \\
\hline Uganda & Started & Policy available for review & TWG formed & NLSP 2 \\
\hline Zambia & Started & - & TWG formed & NLSP 1 \\
\hline Zimbabwe & Started & Available for review & NLSP 1 & NLSP 1 \\
\hline Angola & Started & - & Discussion started & NLSP 1 \\
\hline Benin & Not started & First policy expired in 2007 & Not started with discussion & Not started with discussion \\
\hline Burkina Faso & Not started & - & Not started with discussion & NLSP 1 \\
\hline Burundi & Not started & - & Not started with discussion & NLSP 1 \\
\hline Central African Republic & Not started & - & Not started with discussion & Not started with discussion \\
\hline Cameroon & Started & - & Discussion started & NLSP 1 \\
\hline Chad & Not started & - & Not started with discussion & Not started with discussion \\
\hline Côte d'Ivoire & Started & Not available for review & NLSP 1 & NLSP 1 \\
\hline Comoros & Not started & - & Not started with discussion & No further information available \\
\hline Guinee Conakry & Not started & - & Not started with discussion & NLSP 1 \\
\hline Madagascar & Not started & - & Not started with discussion & No further information available \\
\hline Mali & Started & - & Discussion started & NLSP 1 \\
\hline Mauritania & Not started & - & Not started with discussion & No further information available \\
\hline Mozambique & Started & Available for review & NLSP 1 & NLSP1 \\
\hline Niger & Not started & $\begin{array}{l}\text { Policy validated in } 2012 \text { after } \\
\text { the end of data collection }\end{array}$ & Not started with discussion & No further information available \\
\hline Rwanda & Started & Available for review & NLSP1 & NLSP 2 \\
\hline Senegal & Not started & - & Not started with discussion & TWG formed \\
\hline Togo & Not started & First policy expired in 2006 & Not started with discussion & Started discussion \\
\hline
\end{tabular}

NLSP, national laboratory policy and strategic plan; TWG, technical working group.

Seventeen countries are classified as 'not started' when they have not started the discussion for the development of their national laboratory strategic plans. All other countries are classified as 'started'. 
Supplementary Table 2: Evidence for laboratory workforce shortage and attrition provided in national policies and plans

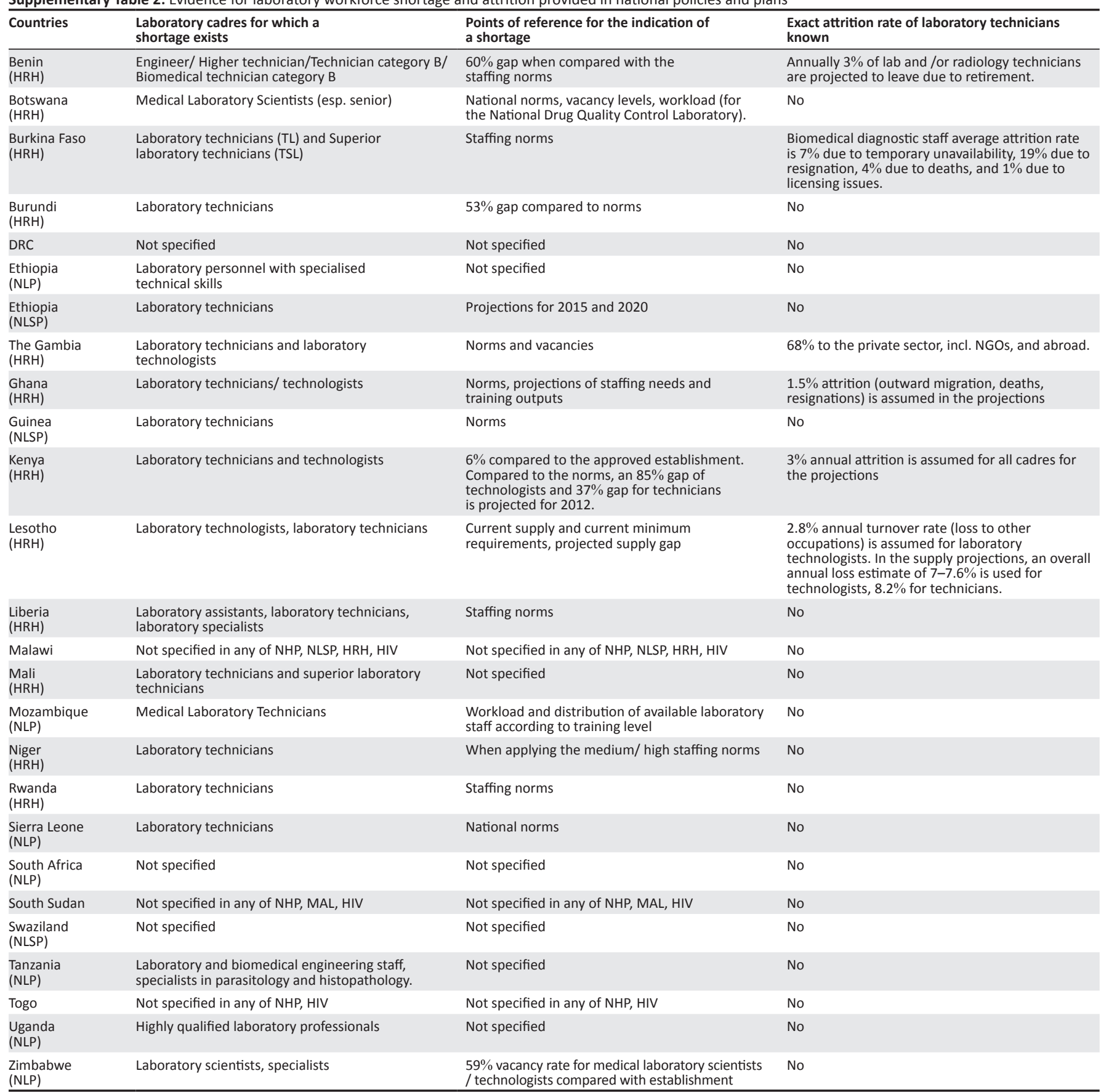

HRH, Human Resources for Health; MAL, national malaria policy or strategy; NHP, national health plan; NLP, national laboratory plan; NLSP, national laboratory policy and strategic plan. 


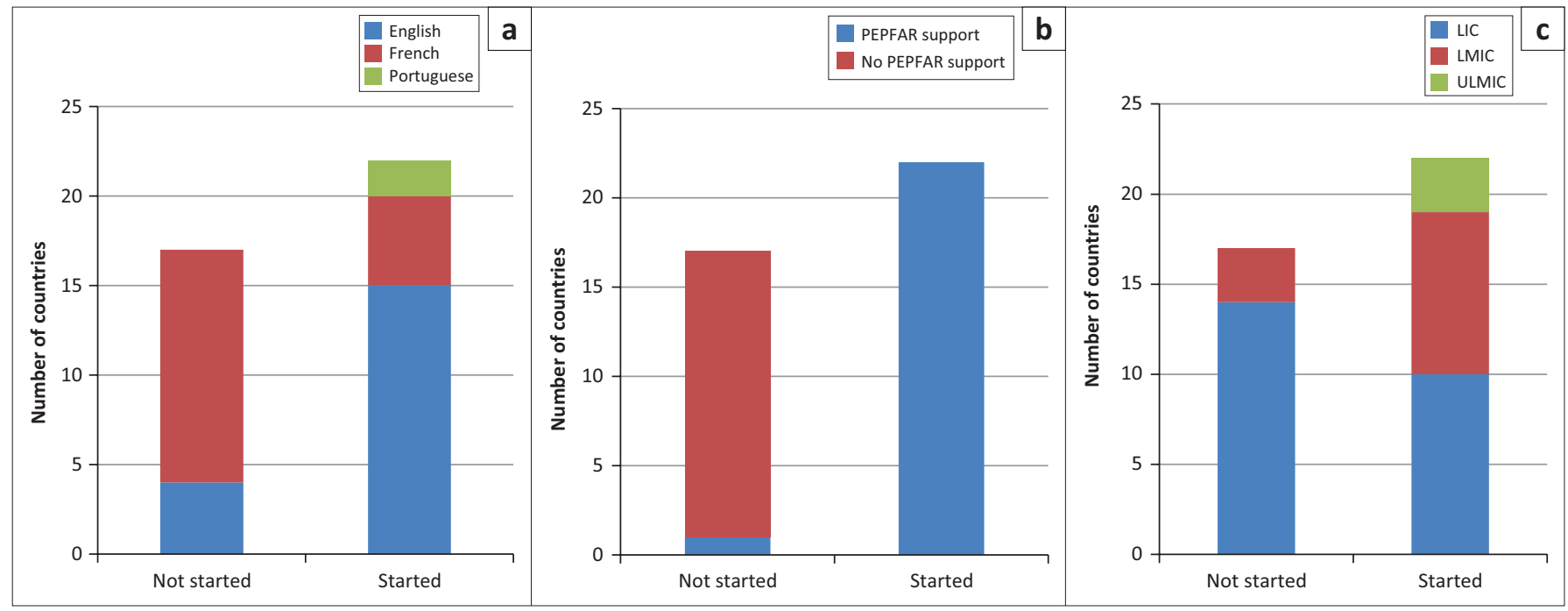

LMIC, low- and middle-income countries; MIC, middle-income countries; PEPFAR, US President's Emergency Plan for AIDS Relief; ULMIC, upper-middle, low- and middle-income countries.

Supplementary Figure 1: Comparison of groups of countries that have started versus not started the process of implementing a national laboratory policy and strategic plan.

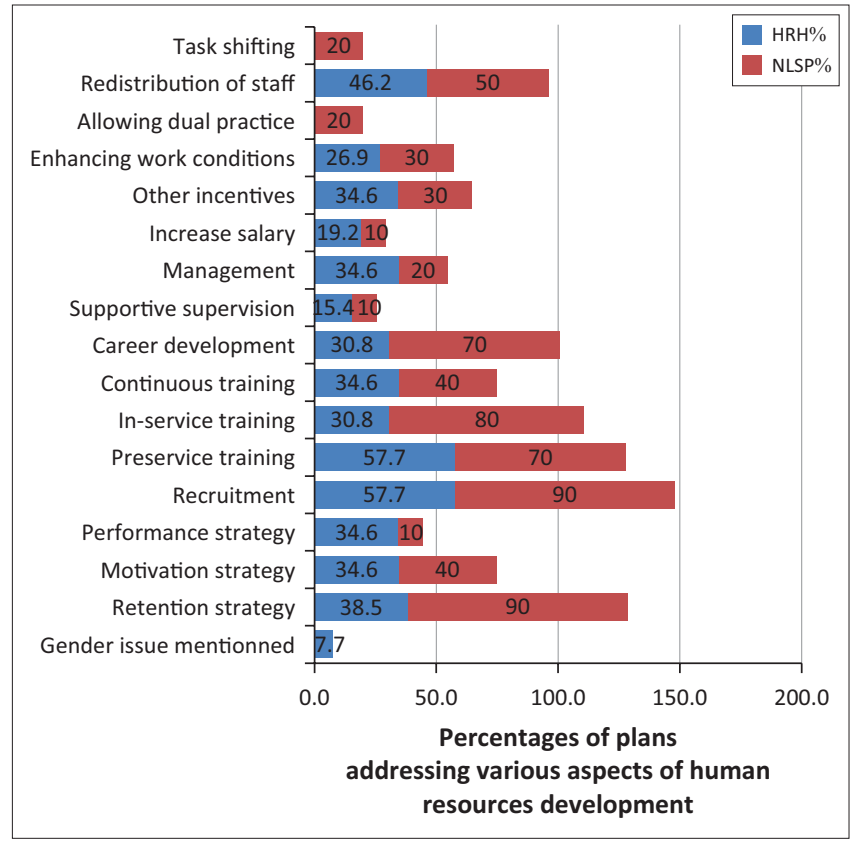

HRH, human resources for health policy/plan; NLSP, national laboratory policy and strategic plan. Supplementary Figure 2: Aspects of human resources development addressed in $10 \mathrm{NLSP}$ and $25 \mathrm{HRH}$. 